NBER WORKING PAPER SERIES

WAGES AND WORKING CONDITIONS

Henry Saffer

Working Paper No. 1418

NATIONAI, BUREAU OF ECONOMIC RESEARCH

1050 Massachusetts Avenue

Cambridge, MA 02138

August 1984

The research reported here is part of the NBER's research program in Health Economics. Any opinions expressed are those of the author and not those of the National Bureau of Economic Research. 
The concept of a compensating difference has been an accepted theory since the time of Adam Smith. As applied to competitive labor markets, this theory states that, ceteris paribus, a wage difference occurs as compensation for the various positive and negative working conditions associated with employment. Considerable research effort has been expended in search of empirical evidence for this theory. In reviews of the empirical literature, Smith (1979) and Brown (1980) both report that the evidence is inconclusive. The failure to find consistent empirical evidence of the theory is attributed to problems paper is to provide an alternative empirical method of measuring the value of working conditions and to test for the existence of a compensating difference.

The usual empirical approach to testing for a compensating difference is to define an empirical model with some measure of income as the dependent variable and a set of human capital, demographic and working conditions variables as regressors. The working conditions variables measure undesirable job attributes and are therefore expected to have a positive affect on income.

The biases associated with this technique are due to the omission of ability data, the omission of some relevant working conditions data and measurement error in the included working conditions data. First, if ability is positively correlated with income and with nonpecuniary compensation, the exclusion of ability data will create an upward bias in the included variables. Second, if any excluded working condition 
is correlated with income and the included working conditions, then the included variables are biased. The direction of bias due to omitted working conditions data depends on the correlation between the excluded and included variables. Finally, a measurement error problem occurs as a consequence of using working conditions data as proxies for nonpecuniary compensation.

Two types of working conditions data are available and the specification of the measurement error problem is dependent on which type is chosen. The most frequently used data are derived from external sources, such as industry-occupation specific accident rates. When this type of data are used, a measurement error is introduced as a result of assigning an average value to all individuals in a particular category. The second type of working conditions data is subjective self-reported data. When this type of data is used, the lack of a known measurement scale introduces measurement error.

Brown (1980) improved the standard empirical approach to measuring compensating differences by using a first difference specification. The data he used measure all variables at two points in time. For each variable, the difference specification uses the change in values between the two time periods. Variables that do not change with time are canceled from the equation. Ability is assumed not to change with time and, therefore, is unrelated to both the change in income and the change in working conditions.

The difference specification used by Brown also eliminates potential selection bias. Selection bias will occur if any. individuals in the first period sample are not included in the second period sample and if the selection process is systematically related 
to individual characteristics. This type of selection process will introduce uncontrolled heterogeneity into a cross sectional equation estimated with the selected sample. Since the difference specification uses only the selected sample and subtracts the first period equation from the second period equation, selection heterogeneity will be canceled.

Brown measured working conditions with data derived from external sources. This type of working conditions data contains an additive meaasurement error due to the assignment of an average value to all individuals in each aggregate. In Brown's empirical model, if an individual does not switch jobs, measured working conditions do not change and, therefore, these working conditions will be canceled. If individuals do switch jobs, a second measurement error is introduced with the new working conditions data. The two measurement errors are uncorrelated across time and, thus, will not cancel. Brown's empirical results provide no evidence of a compensating difference. Duncan and Holmlund (1983) also attempt to find empirical evidence of the compensating difference theory. Like Brown, they also use the difference specification. However, unlike Brown, Duncan and Holmlund measure working conditions with subjective self-reported data. They assume that the relationship between the observed working conditions data and the actual values can be characterized by an additive error term. That is, $w^{*}=w^{*}+e$, where $w$ is the observed value, $w^{*}$ is the actual value and $e$ is an error term. Under this assumption, the difference specification will reduce the measurement error bias in proportion to the correlation of the error terms in the two time periods. 
The usual assumption about subjective self-reported data however, is: $w=a w^{*}+e$, where $a$ is a scale parameter. ${ }^{1}$ The subjective nature of the data requires the inclusion of a multiplicative scale term. The difference specification will not eliminate this scale term. Duncan and Holmlund's empirical results show some evidence of a positive relationship between wage growth and an increase in the unpleasantness of work. Of the 12 working conditions variables used, nine have the expected sign but only three are significant.

This paper presents another extension of the approach initiated by Brown. As in Brown's work, the wage change specification is used to control for bias due to omitted ability data. Then, as in Duncan and Holmlund's study, working conditions are measured using subjective self-reported data. However, in this paper, working conditions are measured by a single comprehensive variable. This approach eliminates omitted working conditions as a source of bias. The working conditions measure is then treated as an unobserved variable which limits measurement error to an unknown scale factor. The model is estimated using a technique derived by Amemiya (1978).

\section{EMPIRICAL SPECIFICATION}

The data set used to test for a compensating difference was the 1973-1977 Quality of Employment Survey (QES). Conducted by the University of Michigan, the QES is a national sample of 1455 individuals, 16 years of age or older, who worked for pay 20 or more hours per week in 1973. These individuals were interviewed again in 1977. The QES contains a number of demographic, human capital and 
labor market variables for both 1973 and 1977 .

Specification of an empirical model with a single unobserved working conditions variable, $w^{\star}$, first requires definition of the unobserved variable. This variable is defined by assuming that each employment situation provides a vector of working conditions and that each individual attaches a subjective weight to these working conditions. ${ }^{2}$ Let $w^{*}$ be defined as the sum of these subjectively weighted working conditions, with larger values of $w^{*}$ indicating less favorable working conditions.

Given a working conditions variable, the compensating difference hypothesis can be tested in two ways. First, $w^{*}$ can be included as a regressor with human capital and demographic variables in an earnings equation. A positive and significant coefficient for $w^{\star}$ would be evidence of a compensating difference. Second, the hypothesis can be tested by specifying a working conditions equation with income and other variables as regressors. In this case, a positive and significant coefficient for income would provide evidence of a compensating difference. These two behavioral relationships form a structural model with earnings and working conditions as jointly determined endogenous variables.

The estimation problem is summarized by the following simultaneous model :

$$
\begin{aligned}
& \text { (1) } y=w^{\star} g_{1}+x_{1} b_{1}+u_{1} \\
& \text { (2) } w^{\star}=y_{2}+x_{2} b_{2}+u_{2}
\end{aligned}
$$

where all variables are specified as the change between 1977 and 1973, 
$x_{i}$ are exogenous variable matrices, $y$ is income, $g_{i}$ and $b_{i}$ are coefficient vectors, $u_{i}$ are error vectors and $i$ equals one and two.

Because $w^{\star}$ is an unobserved variable, estimation requires introduction of an observable indicator variable. However, $w^{*}$ is defined as an index of all working conditions, observable and unobservable. No specific observed working conditions variable is thus adequate as an indicator variable. However, the QES contains a generalized working conditions variable which can act as the indicator.

This variable which measures exposure to any unhealthy or dangerous working condition is a function of both observable and unobservable working conditions and both objective and subjective aspects of these working conditions. Using the 1977 and 1973 data, a dichotomous indicator, $w$, was constructed. If the respondents report a deterioration in their working environment, then $w=1$ and otherwise $w=\emptyset$. Since these data are subjective, the relationship between $w$ and $w^{*}$ must be defined as :

$$
\begin{aligned}
& \text { if } w=1 \text { then } a w^{\star}+e>\emptyset \text { and } \\
& \text { if } w=\emptyset \text { then } a w^{\star}+e \leq \emptyset
\end{aligned}
$$

where a is a scale parameter, $e$ is an error term with $E(e)=\emptyset$ and e is uncorrelated with $u_{1}$ and $u_{2}$.

A technique for consistent and efficient estimation of this type of model is provided by Amemiya (1978). 3 This method requires that the reduced form of the model be estimated. Let the reduced form be defined as: 


$$
\begin{aligned}
& \text { (3) } y=X P_{1}+v_{1} \\
& \text { (4) } w^{*}=X P_{2}+v_{2}
\end{aligned}
$$

where $P_{i}$ are coefficient vectors, $X$ is the data matrix of all exogenous variables in the structural model and $v_{i}$ are error vectors. Equation (3) is estimated by least squares and, using $w$ in place of $w^{*}$, equation (4) is estimated by probit.

Next define $M_{i}$ such that $X M_{i}=x_{i}$. Using (3) and (4), the structural equations can be written as:

$$
\begin{aligned}
& \text { (5) } \hat{\mathrm{P}}_{1}=\hat{\mathrm{H}}_{1} \mathrm{a}_{1}+\mathrm{n}_{1} \\
& \text { (6) } \hat{\mathrm{P}}_{2}=\hat{\mathrm{H}}_{2} \mathrm{a}_{2}+\mathrm{n}_{2}
\end{aligned}
$$

where $\hat{\mathrm{H}}_{1}=\left(\hat{\mathrm{P}}_{2}, \mathrm{M}_{1}\right), \hat{\mathrm{H}}_{2}=\left(\hat{\mathrm{P}}_{1}, \mathrm{M}_{2}\right), \mathrm{a}_{1}=\left(g_{1}, \mathrm{~b}_{1}\right), \mathrm{a}_{2}=\left(g_{2}, \mathrm{~b}_{2}\right)$ and $\mathrm{n}_{i}$ are error vectors. As Amemiya suggests, (5) and (6) are estimated by generalized least squares using the inverse of the covariance matrices of the error terms as weight matrices. These covariance matrices are estimated from the error vectors and coefficient vectors of the reduced form equations.

The selection of variables in the $x_{1}$ matrix was guided by prior theoretical and empirical work on the causal determination of income. Since considerable research has established human capital as a primary determinant of income, several measures of human capital were included in $\mathrm{X}_{1}$. These variables are years in the labor force (EXP), its square (EXPSQ) and years of schooling (ED). Each of these variables was computed as the change between 1977 and 1973. In addition, because human capital theory suggests that these variables have a linear 
relationship with the log of income, income will be specified in log form (lny).

The final variable included in $x_{1}$ is suggested by the theory of compensating differences. Equation (1) represents the envelope of isocompensation functions and isoprofit functions. A variable is required to fix the position of this envelope since the underlying functions shift over time. To control the envelope, the variable included in $\mathrm{X}$ is the change in job satisfaction (JOBSAT) between 1977 and 1973. Freeman (1978) argues that job satisfaction is a function of income, other observed variables and unobserved working conditions. 4 Given Freeman's argument, job satisfaction is an index of total compensation derived from employment. The inclusion of JOBSAT in $x_{1}$ holds total compensation constant and thus helps control the position of the envelope.

The selection of variables for the $x_{2}$ matrix was guided by job matching theory. ${ }^{5}$ This theory assumes that individuals, when accepting a job offer, have only imperfect information about the working conditions associated with the job. Individuals with greater skill in acquiring and interpreting job information should thus be better able to avoid jobs with less desirable working conditions. The variables chosen to measure skill in job matching are education (ED) and age $(A G E 73)$. Education is defined as in $x_{1}$ and age is measured as age in 1973. The change in education is included as a measure of the change in general knowledge and age is included under the assumption that younger workers experience proportionally greater increases in job matching skill than do older workers. Also included in $\mathrm{x}_{2}$ are dichotomous quit (QUIT) and layoff (LAY) variables. The quit variable 
is set equal to one if the individual reports quitting the job held in 1973. Similarly, the layoff variable is set equal to one if the individual reports a permanent layoff from the 1973 job. Both of these variable are included as measures of prior success in job matching. The job satisfaction variable is also included in $x_{2}$ to fulfill the same role as in $x_{1}$.

Column (1) of Table 1 contains the sample means for all variables. Of the initial 1455 observations, 303 were deleted because the individual was self-employed in 1973, over $6 \emptyset$ years old in 1973, or had randomly missing data for 1973. In addition, 487 observations were deleted if 1977 data were unavailable. ${ }^{6}$ The remaining sample contains 665 observations.

\section{RESULTS}

In Table 1, the estimation results for the reduced form earnings equation are shown in column (2) and the estimation results for the reduced form total compensaion equation are shown in column (3). The coefficients in column (2) form the vector $\hat{P}_{1}$ and the coeffients in column (3) form the vector $\hat{\mathrm{P}}_{2}$. As reduced form coefficients, these values have no behavioral interpretation but, along with the reduced form variances and covariances, are necessary for estimation of the structural model.

The computation of the coefficients of the structural model represented by equations (1) and (2) requires estimation of equations (5) and (6). Using GLS, the coefficients of equations (5) and (6) were estimated and then used to compute the coefficients of equations 
(1) and (2). The results of these computations for equations (1) and (2) are reported in Table 1, columns (4) and (5), respectively. The empirical test of the compensating difference theory is provided by the coefficient of $w^{*}$ in equation (1) and by the coefficient of lny in equation (2). These coefficients are reported in columns (4) and (5) of Table 1, respectively, and both

coefficients, as predicted by the theory, are positive, although only $w^{*}$ is significant. Positive coefficients imply that, ceteris paribus, a worsening of working conditions has a positive effect on earnings. Because $w^{\star}$ is an unobserved variable, its coefficient can only be estimated up to a scale factor. Therefore, discussion of the magnitude of the compensating difference is not meaningful.

The lack of significance of lny in equation (2) is possibly the result of uncontrolled variance in $w^{*}$. If the $x_{2}$ variables do not adequately control exogenous variation in $w^{*}$, then the coefficient of lny will be biased. Since economists have devoted considerably more effort to explaining wages than to explaining working conditions, the earnings equation should be considered as the better test of the compensating difference theory.

The coefficients of the exogenous variables in the structural earnings equation are reported in column (4) of Table 1. The experience variable shows the effect of labor force withdrawal or unemployment on wage growth. Setting the derivative of lny, with respect to EXP, equal to zero and solving for EXP shows a negative change in income for those individuals who were out of work for more than 1.42 years. As expected, an increase in education is found to have a positive effect on wage growth. The equation $R^{2}$ is quite low, 
but this is a common problem for difference specification models. The coefficients of the exogenous variables in the structural working conditions equation are reported in column (5) of Table 1 . Education and age were included as job match variables. Both variables are only marginally significant but have the expected signs. Of the two prior match variables, QUIT and LAY, only QUIT is significant. The positive sign of the quit variable indicates that quitting the 1973 job resulted in a worsening of working conditions. Again, the equation's $\mathrm{R}^{2}$ is relatively small.

The structural model was also tested for sensitivity to specification. The alternative specifications included use of the linear and double log form for income and the inclusion of a marriage and health variable as additional exogenous variables. None of these changes, nor any permutations, improved the reported results.

\section{CONCLUSIONS}

Past attempts to find empirical evidence of a compensating difference have been hindered by problems with omitted variables and measurement error. Brown was the first to suggest a wage change formulation to cancel the effects of time invariant omitted variables. However, Brown's working conditions data contain a time variant measurement error wich biased the results. Duncan and Holmlund also use a wage change formulation to test for a compensating difference. Their working conditions data contain a multiplicative measurement error which is not canceled by the change specification. The wage change specification used in these studies does not address the 
problem of omitted working conditions nor does either study provide clear empirical evidence of a compensating difference.

The methodology used in this paper eliminates the bias due to omitted ability data, omitted working conditions data and measurement error. First, a wage change specification is used to eliminate bias due to omitted ability data. Second, a single comprehensive measure of working conditions is used to eliminate bias due to omitted working conditions data. Finally, working conditions are treated as an unobserved variable which restricts measurement error to a scale factor in the estimated coefficients. The empirical results show a positive relationship between changes in income and changes in working conditions. 
Table 1

Means and Estimated Coefficients ${ }^{a}$

\begin{tabular}{|c|c|c|c|c|c|}
\hline \multirow[b]{2}{*}{ Variable } & \multirow[b]{2}{*}{$\begin{array}{c}\text { Means } \\
\text { (1) }\end{array}$} & \multicolumn{2}{|c|}{ Reduced Form } & \multicolumn{2}{|c|}{ Structural Model } \\
\hline & & $\begin{array}{l}\ln y \\
(2)\end{array}$ & $\begin{array}{c}w \\
(3)\end{array}$ & $\begin{array}{l}\ln y \\
(4)\end{array}$ & $\begin{array}{l}w^{*} \\
(5)\end{array}$ \\
\hline$w^{*}$ & .13 & - & - & $\begin{array}{r}.3679 \\
(2.46)\end{array}$ & - \\
\hline Iny & .44 & - & - & - & $\begin{array}{r}.1569 \\
(.17)\end{array}$ \\
\hline EXP & 3.46 & $\begin{array}{r}-.2142 \\
(2.78)\end{array}$ & $\begin{array}{r}-.0405 \\
(.22)\end{array}$ & $\begin{array}{r}-.1911 \\
(1.86)\end{array}$ & - \\
\hline EXPSQ & 13.32 & $\begin{array}{r}.0429 \\
(2.54)\end{array}$ & $\begin{array}{r}.0092 \\
(.23)\end{array}$ & $\begin{array}{r}.0388 \\
(1.73)\end{array}$ & - \\
\hline ED & .23 & $\begin{array}{r}.0861 \\
(3.29)\end{array}$ & $\begin{array}{r}-.1543 \\
(2.53)\end{array}$ & $\begin{array}{r}.1348 \\
(3.54)\end{array}$ & $\begin{array}{r}-.1683 \\
(1.59)\end{array}$ \\
\hline QUIT & .24 & $\begin{array}{r}-.0220 \\
(.48)\end{array}$ & $\begin{array}{r}.2614 \\
(2.37)\end{array}$ & - & $\begin{array}{r}.2642 \\
(2.09)\end{array}$ \\
\hline JOBSAT & .04 & $\begin{array}{r}.0266 \\
(1.17)\end{array}$ & $\begin{array}{r}-.2063 \\
(3.82)\end{array}$ & $\begin{array}{r}.0873 \\
(2.39)\end{array}$ & $\begin{array}{r}-.2108 \\
(3.15)\end{array}$ \\
\hline AGE73 & 35.80 & $\begin{array}{r}-.9072 \\
(4.12)\end{array}$ & $\begin{array}{r}-.01 \varnothing 7 \\
(2.59)\end{array}$ & - & $\begin{array}{r}-.6696 \\
(1.25)\end{array}$ \\
\hline LAYY &.$\varnothing 4$ & $\begin{array}{r}-.0818 \\
(.88)\end{array}$ & $\begin{array}{r}-.2532 \\
(1.17)\end{array}$ & - & $\begin{array}{r}-.2406 \\
(.91)\end{array}$ \\
\hline intercept & - & $\begin{array}{r}.8574 \\
(8.36)\end{array}$ & $\begin{array}{r}-.7505 \\
(3.08)\end{array}$ & $\begin{array}{r}.9045 \\
(5.29)\end{array}$ & $\begin{array}{r}-.8738 \\
(1.34)\end{array}$ \\
\hline $\mathrm{R}^{2}$ & - & .06 & .03 & .02 & .03 \\
\hline
\end{tabular}

a) The $t$ values are reported in parentheses. 
FOOTNOTES

1. See Lee (1982) and Muthen (1983) for additional discussion of this assumption.

2. Research papers on compensating differences often paraphrase the first paragraph of Chapter Ten in Smith's Wealth of Nations. This paragraph outlines the concept of a compensating difference. Referring to the observed differences in wages, Smith goes on in the second paragraph to state "...this difference arises partly from certain circumstances in the employments themselves, which, either really, or at least in the imaginations of men, make up for a small pecuniary gain in some, and counter-balance a great one in others..." . In other words, Smith believes that subjectivity is part of the measurement of nonpecuniary compensation.

3. Amemiya's estimation technique is conceptually similar to, but more efficient than, Heckman's technique.

4. The change in job satisfaction is an ordered categorical and subjective variable. This variable can be assumed to have a monotonic relationship with a latent total compensation variable. However, the job satisfaction variable is used without attempting to construct the latent counterpart because these data act only as exogenous controls.

5. Working conditions data should be excluded from the $x_{2}$ matrix since these data are implicitly included in $w^{*}$. The $x_{2}$ matrix should contain only variables which are causal determinants of $w^{\star}$.

6. The deletion of data resulting from the failure to reinterview in 1977 introduces a potential selection bias if these data were used to estimate separate equations for 1973 and 1977 . However, as explained in the text, any selection heterogeneity in the separate cross sections is canceled from the difference specification. 


\section{REFERENCES}

Amemiya, T. (1978). "The Estimation of a Simultaneous Equation Generalized Probit Model." Econometrica 46(5):1193-2ø5.

Bartel, A. (1981). "Race Differences in Job Satisfaction A Reappraisal." Journal of Human Resources $16(2): 294-303$.

Brown, C. (1980). "Equalizing Differences in the Labor Market." The Quarterly Journal of Economics $94(1): 113-34$.

Duncan, G. (1976). "Earnings Functions and Nonpecuniary Benefits." Journal of Human Resources $11(4): 462-83$.

and Holmlund B. (1983). "Was Adam Smith Right After All?

Another Test of Compensating Wage Differentials." Journal of

Labor Economics 1(4):366-79.

Freeman, R. (1978). "Job Satisfaction as an Economic Variable." American Economic Review 68(2):135-41.

Heckman, J. (1978). "Dummy Endogenous Variables in a Simultaneous Equation System." Econometrica 46(6):931-59.

Lee, L. (1982). "Health and Wage: A Simultaneous Equation Model with Multiple Discrete Indicators." International Economic Review $23(1): 199-221$.

(1981). "Fully Recursive Probability Models and Multivariate Log-Linear Probability Models for the Analysis of Qualitative Data." Journal of Econometrics $16(1): 51-69$.

Muthen, B. (1983). "Latent Variable Structural Equation Modeling with Categorical Data." Journal of Econometrics 22(112):43-65.

Smith, R. (1979). "Compensating Wage Differentials and Public Policy: A Review." Industrial and Labor Relations Review 32(3):339-51.

University of Michigan, Institute for Social Research, (1979). Quality of Employment Survey, Available Data, Ann Arbor, MI. 